
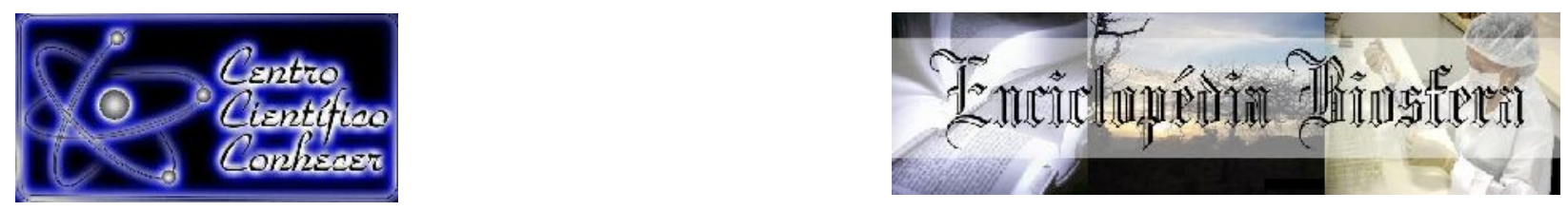

\title{
IDENTIFICAÇÃO DE ISOLADOS DE FUSARIUM ENCONTRADOS EM GRÃOS DE MILHO DURANTE O ARMAZENAMENTO EM SILOS NO ESTADO DO ACRE
}

Romaína Idayara Silva de Araújo ${ }^{1}$, Camila Ferreira Martins Freire ${ }^{2}$ Samuel Cavalcante da $\mathrm{Cruz}^{3}$ Leila Priscila Peters ${ }^{4}$ Josimar Batista Ferreira ${ }^{5}$

${ }^{1}$ Mestranda em Ciência e Inovação Tecnológica pela Universidade Federal do Acre (UFAC), Campus Rio Branco, Rio Branco - AC. E-mail: romainaidayara@gmail.com

${ }^{2}$ Doutoranda em Produção Vegetal pela Universidade Federal do Acre (UFAC), Campus Rio Branco, Rio Branco - AC.

${ }^{3}$ Graduando em Engenharia Florestal pela Universidade Federal do Acre (UFAC), Campus Rio Branco, Rio Branco - AC.

${ }^{4}$ Pós-doutoranda em Ciência e Inovação Tecnológica pela Universidade Federal do Acre (UFAC), Campus Rio Branco, Rio Branco - AC

${ }^{5}$ Professor associado a Universidade Federal do Acre (UFAC), Centro de Ciências Biológicas e da Natureza (CCBN), Campus Rio Branco, Rio Branco - AC

Recebido em: 15/11/2021 - Aprovado em: 15/12/2021 - Publicado em: 30/12/2021 DOI: 10.18677/EnciBio_2021D30

trabalho licenciado sob licença Creative Commons Attribution-NonCommercial-NoDerivatives 4.0 International License.

\section{RESUMO}

Uma das mais importantes e antigas culturas agrícolas é o milho, em função do seu potencial produtivo, composição química e valor nutricional. Durante o armazenamento em silos, este pode apresentar contaminação por fungos toxigênicos, como Fusarium, Aspergillus e Penicillium. Desta forma, a presente pesquisa teve como objetivo analisar se o período de armazenamento de grãos de milho em silo influencia na incidência de fungos do gênero Fusarium. O experimento foi desenvolvido a partir de coletas de grãos de milho, armazenados em silos graneleiros. As unidades armazenadoras localizam-se nos municípios de Capixaba e Senador Guiomard no Estado do Acre. Assim, analisou-se a incidência de Fusarium em grãos armazenados. Realizou-se a análise de qualidade de grãos, isolamento, identificação fúngica e caracterização morfológica. Os resultados obtidos foram interpretados por meio das análises de variância, a partir do teste de Qui-Quadrado de Pearson, ao nível de significância de $\alpha=0,05$. O gênero Fusarium foi detectado em todas as amostras analisadas, com variação de incidência entre 59,5\% a 74\%, referente ao silo de Capixaba e $62,5 \%$ a $67,5 \%$, concernente ao silo de Senador Guiomard. A identificação morfológica revelou a prevalência do gênero Fusarium em relação aos gêneros Aspergillus e Penicillium, tanto nos grãos ardidos quanto nos assintomáticos. Os resultados evidenciaram que o gênero Fusarium foi o que mais acometeu os grãos de milho. Foram identificados espécies de $F$. solani, $F$. oxysporum e F. verticilioide;

PALAVRAS-CHAVE: Fusarium, milho, silos. 


\title{
IDENTIFICATION OF FUSARIUM ISOLATES FOUND IN CORN GRAIN DURING STORAGE IN SILOS IN THE STATE OF ACRE
}

\begin{abstract}
One of the most important and ancient agricultural crops is corn, due to its productive potential, chemical composition and nutritional value. During storage in silos, it can be contaminated by toxigenic fungi, such as Fusarium, Aspergillus and Penicillium. Thus, this research aimed to analyze whether the storage period of corn grains in silo influences the incidence of fungi of the Fusarium genus. The experiment was developed from the collection of corn grains, stored in bulk silos. The storage units are located in the municipalities of Capixaba and Senador Guiomard in the State of Acre. Thus, the incidence of Fusarium in stored grains was analyzed. Grain quality, isolation, fungal identification and morphological characterization were analyzed. The results obtained were interpreted through analysis of variance, from the Pearson's Chi-Square test, at a significance level of $\alpha=0.05$. The Fusarium genus was detected in all analyzed samples, with an incidence ranging from $59.5 \%$ to $74 \%$, referring to the Capixaba silo and $62.5 \%$ to $67.5 \%$, concerning the Senador Guiomard silo. Morphological identification revealed the prevalence of the genus Fusarium in relation to the genus Aspergillus and Penicillium, both in burnt and asymptomatic grains. The results showed that the Fusarium genus was the one that most affected corn grains. Species of $F$. solani, F. oxysporum and F. verticilioide were identified;
\end{abstract}

KEYWORDS: Fusarium, silos, corn.

\section{INTRODUÇÃO}

Uma das mais importantes e antigas culturas agrícolas produzidas em larga escala em nível mundial, nacional e local é o milho, em função do seu potencial produtivo, composição química e valor nutritivo (NEUMANN, 2017). Tem origem nas Américas, mas é cultivado desde a Rússia até a Argentina, em diferentes latitudes. Tem como base a segurança alimentar da população, uma vez que é utilizado para a alimentação humana e nutrição animal. (SANTOS, 2017; MHATIAS, 2019).

Devido a sua vasta extensão territorial, climas diferenciados por região e amplas bacias hidrográficas, o Brasil tornou-se um país com grande potencial produtivo, por apresentar grande diversidade de cultivares que se adaptam a diferentes climas (CALIXTO JUNIOR, 2017). Entretanto, esta diversidade merece uma atenção maior, tendo em vista que elevadas temperaturas combinadas com alta umidade, como encontradas na região amazônica, podem favorecer 0 desenvolvimento de fungos. Estes podem se desenvolver tanto em campo, quanto durante o armazenamento de matéria-prima produzida para o processamento (VALMORBIDA, 2018).

Desta forma, fungos de campo e armazenamento, como Fusarium, Aspergillus e Penicillium podem contaminar e se disseminar em produtos agrícolas durante o crescimento da planta, ou após a colheita em armazenagem. Estes compostos podem estar presentes, mesmo após a remoção do micélio, uma vez que a maior parte deles são resistentes a tratamentos físicos e químicos (PRESTES, 2019). Assim, a etapa de armazenamento é de grande importância, devido à facilidade de associação com sistemas de secagem com ar forçado (AGBETIAMEH, 2019), pois possibilita a preservação das características, qualidade e viabilidade dos grãos, após a colheita e secagem.

Durante o período de armazenamento, podem-se iniciar processos de deterioração, devido à presença de contaminantes nas fases de pré e pós-colheita, 
tais como, contaminantes físicos, químicos e biológicos. Isso acontece em decorrência de falhas nos processos de armazenagem e de baixa capacidade de estocagem (TARUVINGA, 2014).

Segundo o Sistema Nacional de Aprendizagem Rural, as perdas mundiais no pós-colheita podem atingir $30 \%$ da produção agrícola. No Brasil, as perdas entre a colheita e o armazenamento chegam a $20 \%$ e os prejuízos de qualidade e quantidade ocorrem, principalmente, pela presença de contaminantes de natureza biológica, física e química nas fases de pré e pós-colheita dos grãos, o que afeta cerca de $10 \%$ da produção nacional (SENAR, 2018).

Desta forma, o presente trabalho teve como objetivo analisar influência na incidência de fungos sob o período de armazenamento de grãos de milho em silo, do gênero Fusarium, no estado do Acre.

\section{MATERIAL E MÉTODOS}

O estudo foi desenvolvido a partir de coletas de grãos de milho, armazenados em silos graneleiros. As unidades armazenadoras localizam-se nos municípios de Capixaba e Senador Guiomard no Estado do Acre.

FIGURA 1 . Mapa de localização dos silos graneleiros, referente ao município de Capixaba e Senador Guiomard no estado do Acre.

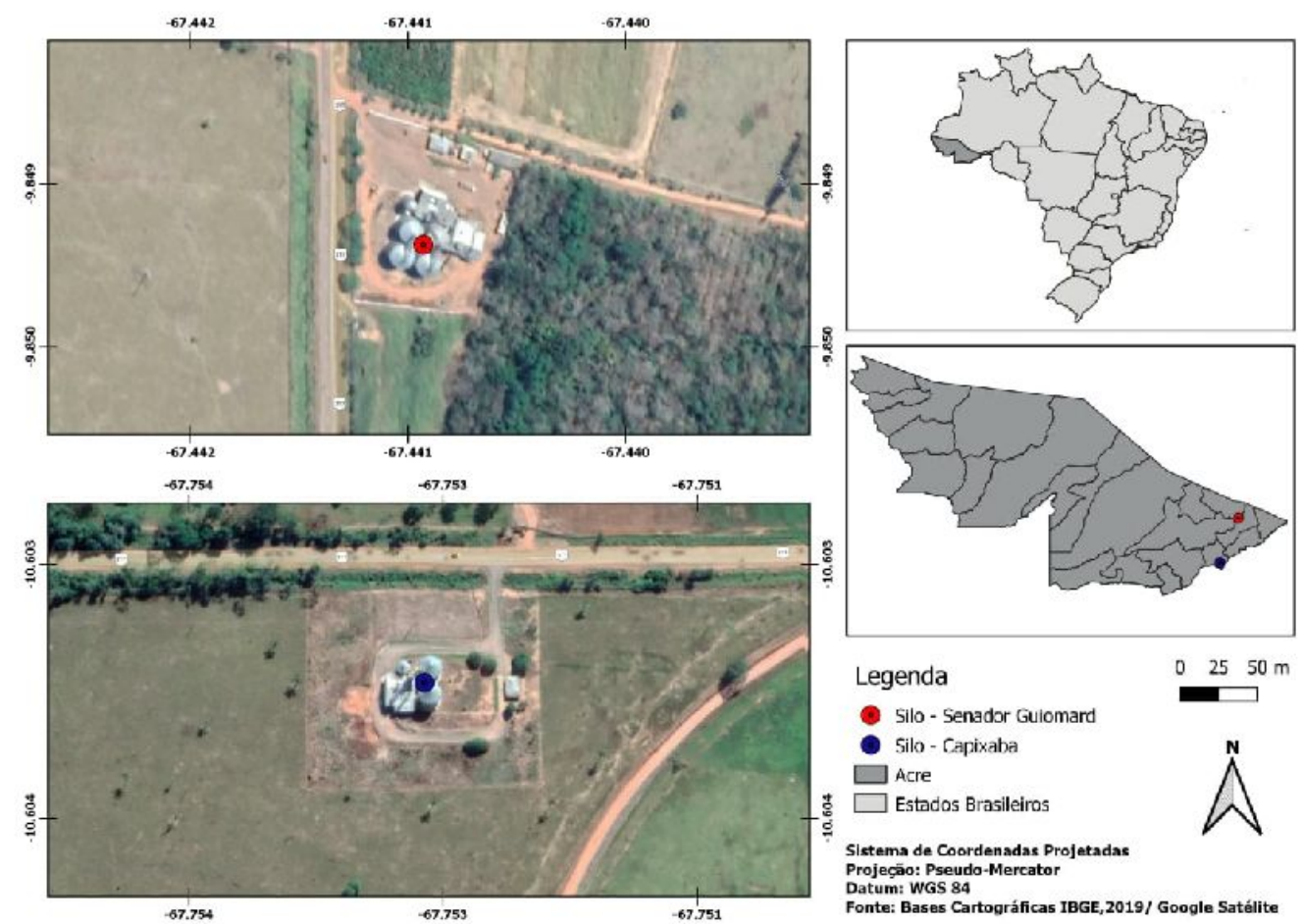

Fonte: Bases Cartográficas IBGE, 2019/Google Satélite.

A coleta da amostra para a análise foi de $3 \mathrm{~kg}$, realizada em três pontos distintos em cada silo (CONAB, 2015), no período de março a dezembro de 2020, sendo feita uma coleta a cada três meses. As amostras foram acondicionadas em uma caixa de isopor, adequadamente vedada e que proporcionava proteção contra impactos mecânicos, calor e luz, a fim de evitar vazamentos e contaminação durante o transporte (MAPA, 2018). 
Foram avaliados os defeitos dos grãos (ardidos, chochos, germinados, fragmentados, quebrados, carunchados, morfados ou fermentados e materiais estranhos/impurezas) por triagem pela metodologia oficial do Ministério da Agricultura do Brasil - Instrução Normativa MAPA oo 60 de 22/12/2011.

A amostra para identificação morfológica dos fungos patogênicos foi realizada com base no MAPA - Manual Regras para Análise de Sementes, $10 \times 20$, sendo 10 o número de repetições em placas de petri contendo meio de cultura BDA, por 20 o número grãos distribuídos em cada placa, para isolamento e identificação fúngica. Totalizando 200 grãos por amostra de silo. A metodologia para a identificação fúngica e caracterização morfológica foi desenvolvida a partir do Guia Prático para Fungos fitopatogênicos, Menezes Maria, 2004.

Os grãos foram imersos, inicialmente, em solução de hipoclorito de sódio $1 \%$, durante 3 minutos; e em seguida, após secagem rápida em papel de filtro esterilizado, distribuídos assepticamente sobre o meio BDA a uma distância de 2-4 $\mathrm{cm}, 20$ sementes por placa de petri. As placas, com grãos, foram colocadas em temperatura ambiente, pelo período de 7-8 dias, sempre monitoras todos os dias, observando a germinação fúngica.

Foi realizada, inicialmente, a técnica de semeadura em meio BDA e depois as amostras foram incubadas. Para inoculação, um fragmento de colônia crescida em BDA foi introduzido no centro da placa contendo meio de cultura. As placas foram incubadas a temperatura ambiente e monitoradas durante 7 dias. Logo após foi realizada a análise macroscópica.

Para a identificação das espécies (Fusarium), fragmentos de colônias crescidas, foram então aplicadas sobre o meio BDA, com sobreposição de uma lamínula, com a técnica de microcultivo, incubadas durante 3 a 7 dias. A lamínula, com parte do crescimento da colônia repicada, foi transferida para uma lâmina contendo corante azul de algodão lactofenol. As estruturas fúngicas coradas foram visualizadas sob um microscópio óptico.

Para a identificação das espécies (Aspergillus e Penicillium), fragmentos de colônias crescidas, foram então aplicadas sobre o meio Czapec, com sobreposição de uma lamínula, com a técnica de microcultivo, incubadas durante 3 a 7 dias. A lamínula, com parte do crescimento da colônia repicada, foi transferida para uma lâmina contendo corante azul de algodão lactofenol. As estruturas fúngicas coradas foram visualizadas sob um microscópio óptico.

$O$ experimento foi conduzido segundo o delineamento inteiramente casualizado (DIC), com arranjo fatorial $2 \times 4$. Os resultados obtidos foram interpretados por meio das análises de variância, a partir do teste de Qui-Quadrado de Pearson, ao nível de significância de $\alpha=0,05$.

A rotina de cálculos para a determinação da referida estatística foi realizada pelo software R. A análise de qualidade de grãos foi desenvolvida com base na Instrução Normativa MAPA no 60 de 22/12/2011.

\section{RESULTADOS E DISCUSSÃO}

Observou-se que ambos os silos, apresentaram valores percentuais próximos em relação aos danos (ardidos, mofados, fermentados e carunchados), a unidade armazenadora de Grãos de Capixaba, apresentou média de 1,1\%, o que foi superior ao de Senador Guiomard, com média de 0,3\%. Os defeitos de grãos ardidos e fermentados até $1 / 4$ são 0 reflexo das podridões das espigas originadas ainda no campo, provenientes da ação fúngica que sob condições favoráveis de 
temperatura, umidade relativa e teor de água, podem acelerar o processo de deterioração durante o armazenamento.

A porcentagem de grãos quebrados foi de $2,6 \%$ no silo de Senador Guiomard, enquanto o silo de Capixaba obteve 1,4\%. Esse defeito, na classificação oficial, é considerado fator de depreciação da qualidade de um lote, por levar a um enquadramento em tipo inferior quando presente em grandes porcentagens.

Para os danos referentes aos grãos gessados, os valores entre as unidades armazenadoras, respectivamente, foram 0,3 e 0,6\%, apresentando-se dispostos com coloração e aspecto de gesso (farináceo). Entre as possíveis causas da formação dessas áreas opacas estariam as de origem genética (PATINDOL; WANG, 2003; GOMES, 2020), condições ambientais adversas, má formação dos grãos pela incidência de doenças, grande quantidade de grãos imaturos, alto grau de umidade e ataque de insetos sugadores (percevejos-do-grão) antes da colheita (PRESTES, 2019).

As Unidades Armazenadoras apresentaram impurezas em todas as amostras analisadas, porém a níveis aceitáveis, desta forma, não trariam danos severos aos lotes. Vale ressaltar que a presença de insetos vivos ou mortos durante o armazenamento pode ocasionar perdas na massa dos grãos, do valor nutritivo e redução do padrão comercial (EMBRAPA, 2007).

TABELA 1. Qualidade de grãos em relação a danos e impurezas do milho (Zea mays L.) produzidas e armazenadas no Estado do Acre.

\begin{tabular}{|c|c|c|c|c|}
\hline \multirow{3}{*}{$\begin{array}{l}\text { Alterações em lotes } \\
\text { de grãos }\end{array}$} & \multicolumn{4}{|c|}{ Qualidade de milho (\%) e Tipo / UAGs } \\
\hline & \multicolumn{2}{|c|}{$\mathbf{A}$} & \multicolumn{2}{|c|}{$\mathbf{B}$} \\
\hline & Média (\%) & Tipo & Média (\%) & Tipo \\
\hline \multicolumn{5}{|l|}{ Danos } \\
\hline \multicolumn{5}{|l|}{ Biológicos } \\
\hline Ardido & 0,7 & I & 1 & I \\
\hline Mofados & 0,7 & I & 0,9 & I \\
\hline Fermentados & 0,3 & I & 1,1 & I \\
\hline Carunchados & 0,3 & I & 0,4 & I \\
\hline \multicolumn{5}{|l|}{ Físicos } \\
\hline $\begin{array}{l}\text { Quebrados }(<5>3 \\
\mathrm{mm})^{\mathrm{a}}\end{array}$ & 1,4 & 1 & 2,6 & I \\
\hline Gessado & 0,3 & I & 0,6 & I \\
\hline Germinado & ND & I & ND & $\mathrm{I}$ \\
\hline Imaturos & 0,3 & I & 0,3 & I \\
\hline \multicolumn{5}{|l|}{ Impurezas } \\
\hline Quebrados $(<3 \mathrm{~mm})^{\mathrm{a}}$ & 0,2 & 1 & 0,4 & I \\
\hline Outros grãos & ND & NA & 0,2 & I \\
\hline Matérias estranhas & 0,5 & $\mathrm{I}$ & 0,9 & 1 \\
\hline Insetos mortos & ND & NA & 0,2 & I \\
\hline $\begin{array}{l}\text { Outras plantas / } \\
\text { sementes }\end{array}$ & 0,1 & I & 0,3 & I \\
\hline
\end{tabular}

Quanto ao tipo de grão, os resultados de classificação (Tabela 2), indicam que mesmo durante um período de nove meses de armazenamento, os grãos mantiveram a qualidade a níveis aceitáveis e foram classificados como Tipo 1. No ENCICLOPÉDIA BIOSFERA, Centro Científico Conhecer - Jandaia-GO, v.18 n.38; p. 136 
Brasil, pela classificação oficial, grãos ardidos juntamente com mofados e brotados são considerados defeitos graves que leva ao enquadramento oficial do milho em tipos 1, 2 e 3 com limites de tolerância máxima de 3\%, 6\% e 10\% respectivamente.

TABELA 2. Classificação dos Grãos de milho

\begin{tabular}{|c|c|c|c|c|c|c|c|c|c|}
\hline \multirow[b]{2}{*}{ Silos } & \multirow[b]{2}{*}{$\begin{array}{l}\text { Matérias } \\
\text { estranhas e } \\
\text { Impurezas }\end{array}$} & \multirow[b]{2}{*}{ Umidade } & \multicolumn{2}{|c|}{ Avariados } & \multirow{2}{*}{ 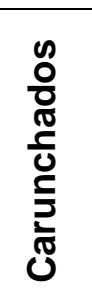 } & \multirow[b]{2}{*}{ 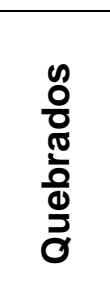 } & \multicolumn{3}{|c|}{ Classificação } \\
\hline & & & Ardidos & Total & & & $\stackrel{\circ}{\stackrel{2}{F}}$ & $\frac{\text { 을 }}{\text { 는 }}$ & 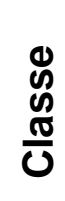 \\
\hline A & $0,54 \%$ & $13,9 \%^{*}$ & 0,75 & 2,08 & 0,3 & 1,41 & 1 & 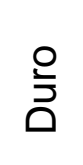 & $\frac{\frac{\pi}{0}}{\frac{\pi}{\sigma}}$ \\
\hline B & $0,84 \%$ & $13,6 \%{ }^{*}$ & 1 & 2,9 & 0,4 & 2,59 & 1 & $\stackrel{\circ}{3}$ & $\begin{array}{l}\frac{\pi}{0} \\
\frac{\pi}{\sigma} \\
\frac{c}{\alpha}\end{array}$ \\
\hline
\end{tabular}

A: Silo Capixaba; B: Silo Senador Guiomard; *A umidade dos grãos de milho deve ser no máximo, 14\%.

\section{Qualidade sanitária e incidência de fungos patogênicos}

Foi observada a incidência dos fungos pertencentes aos gêneros Fusarium, Aspergillus e Penicillium nas amostras de milho referentes às unidades armazenadoras dos municípios de Capixaba e Senador Guiomard.O gênero Fusarium foi detectado em todas as amostras analisadas, com variação de incidência entre $59,5 \%$ a $74 \%$, referente ao silo de Capixaba e $62,5 \%$ a $67,5 \%$, concernente ao silo de Senador Guiomard. As médias de infestação do Fusarium para os silos de Capixaba e Senador Guiomard, respectivamente, foram de 64,02\% e $65,3 \%$ para as quatro coletas realizadas (tabela3).

Observou-se que durante o período de armazenamento, houve uma redução da incidência de Fusarium. No entanto, a maior média amostral em termos de incidência fúngica, quando comparada a outros fungos identificados, foi a do gênero Fusarium. Isso corrobora com a afirmação de Marin et al. (1998) de que o Fusarium spp. tem preferência por substratos com teores de umidade mais elevados.

TABELA 3. Percentual de incidência fúngica (Gêneros versus Silos)

\begin{tabular}{cccc}
\hline \multirow{2}{*}{ Silos } & \multicolumn{3}{c}{ Gêneros (Média percentual de incidência) } \\
\cline { 2 - 4 } Capixaba & 64,02 & Penicillium & Aspergillus \\
\hline $\begin{array}{c}\text { Senador } \\
\text { Guiomard }\end{array}$ & 65,3 & 14,2 & 21,77 \\
\hline \multicolumn{4}{c}{14,8} \\
\hline $\mathbf{x}^{2}=1,18$ & \multicolumn{3}{c}{ Resultados Qui-quadrado } \\
\hline${ }^{*} \mathrm{p}$-valor $>0,05$ & \multicolumn{3}{c}{ df:2 } \\
\hline
\end{tabular}


Os resultados obtidos na correlação do teste Qui-quadrado de Pearson, entre duas variáveis, (gênero versus silos), indicam que não houve interação significativa, uma vez que o $p$-valor foi igual a 0,55 ( $p$-valor $>0,05$ ), considerando normal a distribuição dos gêneros fúngicos identificados durante as coletas. $O$ valor observado $(t=1,18)$ foi menor que o valor esperado $(t=1,96)$, não havendo diferença significativa entre os silos.

Observou-se, durante as coletas, que eram fornecidas aos grãos as mesmas condições de ambientes controlados em ambos os silos, desde a secagem dos grãos, aeração, controle de umidade e temperatura. Desta forma, embora o silo de Senador Guiomard recebesse grãos de vários produtores do Estado do Acre, como também do Amazonas, o que poderia ter favorecido uma maior incidência de fungos toxigênicos, isso não atuou como uma variável determinante, nem gerou níveis de contaminação e disseminação fúngica maiores que o silo de Capixaba.

Quando se apresenta um manejo adequado durante o período de armazenagem de grãos, como a observação da umidade da massa de grãos, que deve ser realizada no momento da entrada dos grãos na unidade de armazenamento e, periodicamente, durante o armazenamento, como também a verificação dos grãos no processo de secagem, observando se apresentam umidade ideal para entrar no silo, se há monitoramento de temperatura e aeração, há um controle nos níveis de incidência fúngica, proporcionando um ambiente seguro e promovendo a qualidade dos grãos (DWEBA, 2017; CONAB, 2018; HAWKINS, 2018).

FIGURA 2. Relação de incidência fúngica dos gêneros Aspergillus, Penicillium e Fusarium, identificados nos silos dos municípios de Capixaba e Senador Guiomard no Estado do Acre.

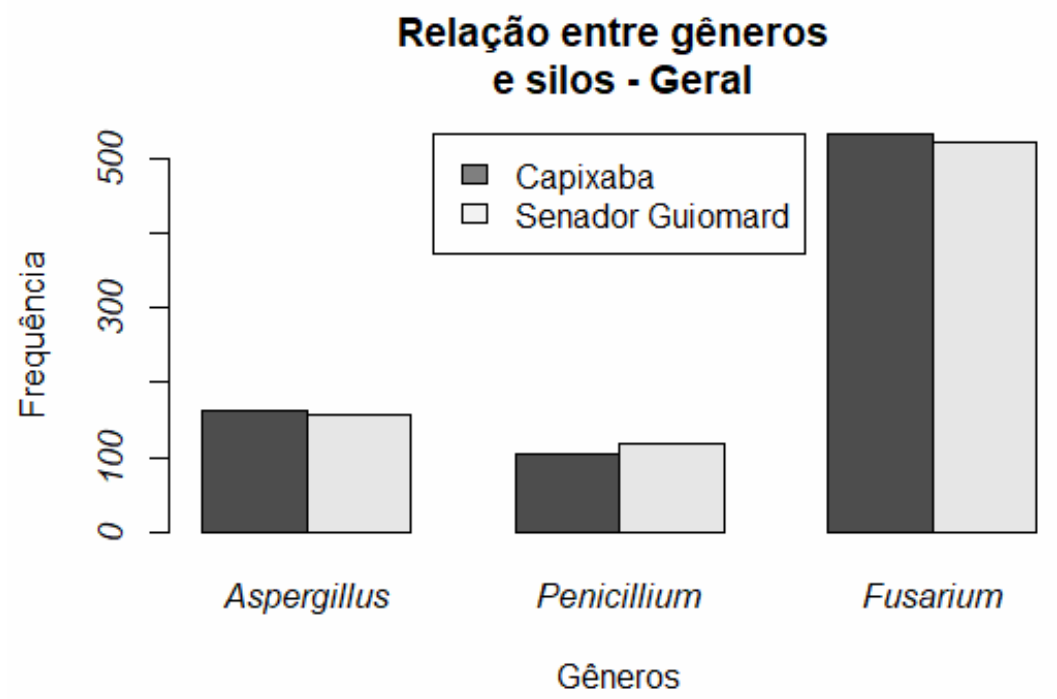

Ao observar a Relação de incidência fúngica entre os gêneros Aspergillus, Penicillium e Fusarium, identificados nos silos de Capixaba e Senador Guiomard, nota-se que a frequência do gênero Fusarium se destaca em ambos os silos em relação aos demais gêneros. 
O gênero Fusarium foi detectado em grãos de milho por outros autores em regiões do Centro-Oeste, Sudeste e Sul do Brasil (MÁRCIA;LAZZARI, 1998; BENTO, 2011; FERREIRA et al., 2014). Os fungos sobrevivem associados às sementes de milho durante um período de 12 meses de armazenamento. Embora haja redução da incidência do gênero Fusarium durante o armazenamento, a presença desse fungo pode acelerar 0 processo de deterioração das sementes/grãos (TANAKA, 2001; MISTURA, 2020).

Um estudo realizado com grãos de armazenamento realizado na cidade de Cuibá-MT em 2015, relatou que houve incidência do fungo Fusarium sp. no decorrer do período de armazenagem (OLIVEIRA, 2017). As amostras apresentaram incidência média de $88,88 \%$ de Fusarium, sendo possível que a contaminação tenha ocorrido ainda em campo. O experimento também apresentou resultados favoráveis a respeito de maior incidência pelo gênero Fusarium quando comparados a outros fungos identificados, com infestação de $60 \%$ a $100 \%$ das amostras.

As condições ambientais (período seco e úmido) durante a coleta dos grãos são apresentadas nas figuras 2 e 3 . Durante o período entre a primeira coleta que ocorreu no mês de março e a última, em dezembro buscou-se observar se os períodos seco e úmido interferiam nos níveis de incidência fúngica, levando em consideração a umidade dos grãos durante as coletas das amostras, que sempre estavam entre 13 a $14 \stackrel{\circ}{\circ} \mathrm{Cem}$ ambos os silos.

FIGURAS 3 e 4. Relação de incidência fúngica dos gêneros Aspergillus, Penicillium e Fusarium, em períodos úmidos e secos nos silos dos municípios de Capixaba e Senador Guiomard no Estado do Acre.

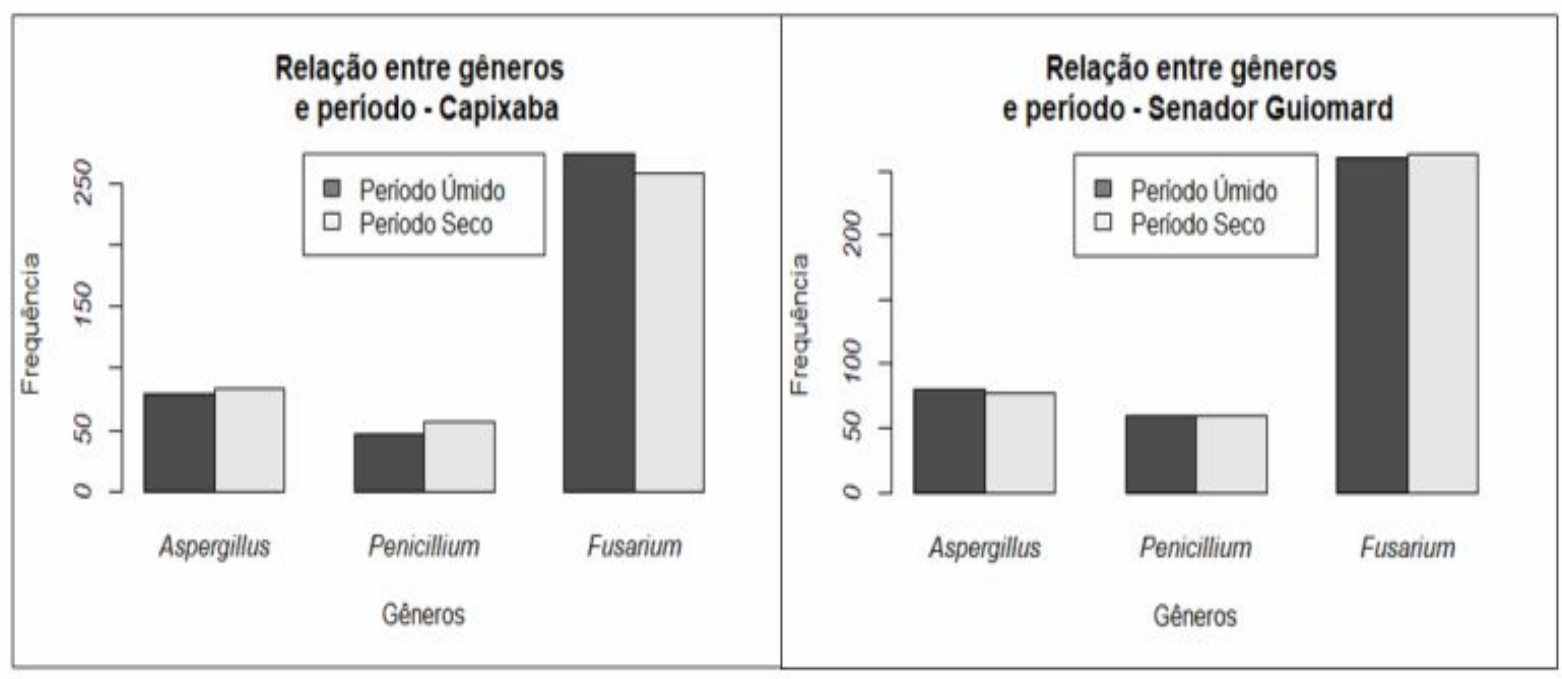

Os resultados obtidos indicam que não houve interação significativa, ( $p$-valor $>0,05)$, considerando normal a distribuição dos gêneros fúngicos durante ambos os períodos. $O$ valor observado $(t=1,54)$ foi menor que $o$ valor esperado $(t=1,96)$, não havendo diferença significativa entre os silos.

Valmorbida (2018), ao desenvolver um estudo referente à incidência fúngica em grãos de milho no período de armazenamento, avaliou quatro unidades armazenadoras de grãos, localizadas no sul do estado de RO (cidade Vilhena), norte do Brasil, observou que embora as regiões dominadas por clima tropical úmido possam favorecer o desenvolvimento de fungos em grãos, na colheita e durante o armazenamento, devido à vulnerabilidade de milho ao ataque de pragas e 
contaminação por fungos (MUNKVOLD, 2017; LUDEMANN, 2020), isso não se aplicou aos resultados da pesquisa, uma vez que a incidência de fungos dos gêneros Fusarium, Aspergillus e Penicillium em períodos de armazenamento não apresentaram influência significativa a serem relacionadas à temperatura ou pluviosidade do Estado de Rondônia.

Os fungos do gênero Aspergillus e Penicillium contaminam os grãos depois da colheita e têm a capacidade de viver associados a grãos com baixo teor de água (BERTUZZI, 2019; TADEI, 2020). De acordo com Lanza (2017) a incidência de Fusarium e Penicillium como os fungos mais presentes nos grãos, seguidos de Aspergillus e Stenocarpella parece ser padrão para o milho brasileiro.

Outra afirmação que possivelmente pode explicar a alta frequência de Fusarium nos grãos de milho é que um microrganismo que se apresenta em maior número ou maior adaptação ao substrato tem vantagem sobre os demais, pois os fungos possuem um antagonismo passivo em que o crescimento é inibido pela competição do espaço e nutrientes fundamentais ao desenvolvimento. Nesse sentido, o Fusarium se apresentou como um forte competidor em relação aos outros gêneros (Aspergillus e Penicillium) (MOTTA et al., 2015; PALHARI, 2019).

Lazzari (1997), disse que os fungos dos gêneros Aspergillus e Penicillium são considerados fungos de armazenamento, que necessitam de teores de água entre 13 e 18\%, respectivamente, para se desenvolverem, sendo sua incidência pouco frequente durante o crescimento no campo e nos grãos recém-colhidos. $O$ que pode explicar o motivo que entre os gêneros identificados nas amostras, estes dois tenham se apresentado inferiores quando comparados aos valores de contaminação de Fusarium.

Foram identificadas três espécies do gênero Fusarium: Fusarium solani, Fusarium oxysporum e Fusarium verticillioides. Ao observar a porcentagem média de incidência das espécies nos silos de Capixaba e Senador Guiomard respectivamente, notou-se que o Fusarium solani obteve maiores médias em ambos os silos $(42,15$ e 45,6\%) e o Fusarium verticillioides obteve valores menores $(17,7$ e $27,75 \%)$.

TABELA 4. Percentual de incidência de espécies de Fusarium.

\begin{tabular}{cccc}
\hline \multirow{2}{*}{ Silos } & \multicolumn{3}{c}{ Espécies } \\
\cline { 2 - 4 } & $\begin{array}{c}\text { Fusarium } \\
\text { solani }\end{array}$ & $\begin{array}{c}\text { Fusarium } \\
\text { oxysporum }\end{array}$ & Fusarium verticilioides \\
\hline $\mathrm{A}$ & 42,15 & 40,15 & 17,7 \\
\hline $\mathrm{B}$ & 45,6 & 26,65 & 27,75 \\
\hline $\mathbf{x}^{2}=27,85$ & $\mathbf{R e s u l t a d o s}$ Qui-quadrado \\
\hline${ }^{*} \mathrm{p}$-valor $<0,05$ & \multicolumn{2}{c}{$\mathbf{p}$-valor $\boldsymbol{\alpha}=8,963\left(10^{-7}\right)$} \\
\hline
\end{tabular}

Os resultados obtidos mostram que houve variação significativa em relação à incidência de espécies de Fusarium durante o período de armazenagem dos grãos, em ambos os silos. O ( $p$-valor $<0,05)$. 
FIGURA 5. Relação de incidência das espécies de Fusarium solani, oxysporum e verticilioides, referente aos silos dos municípios de Capixaba (A) e Senador Guiomard (B) no Estado do Acre.

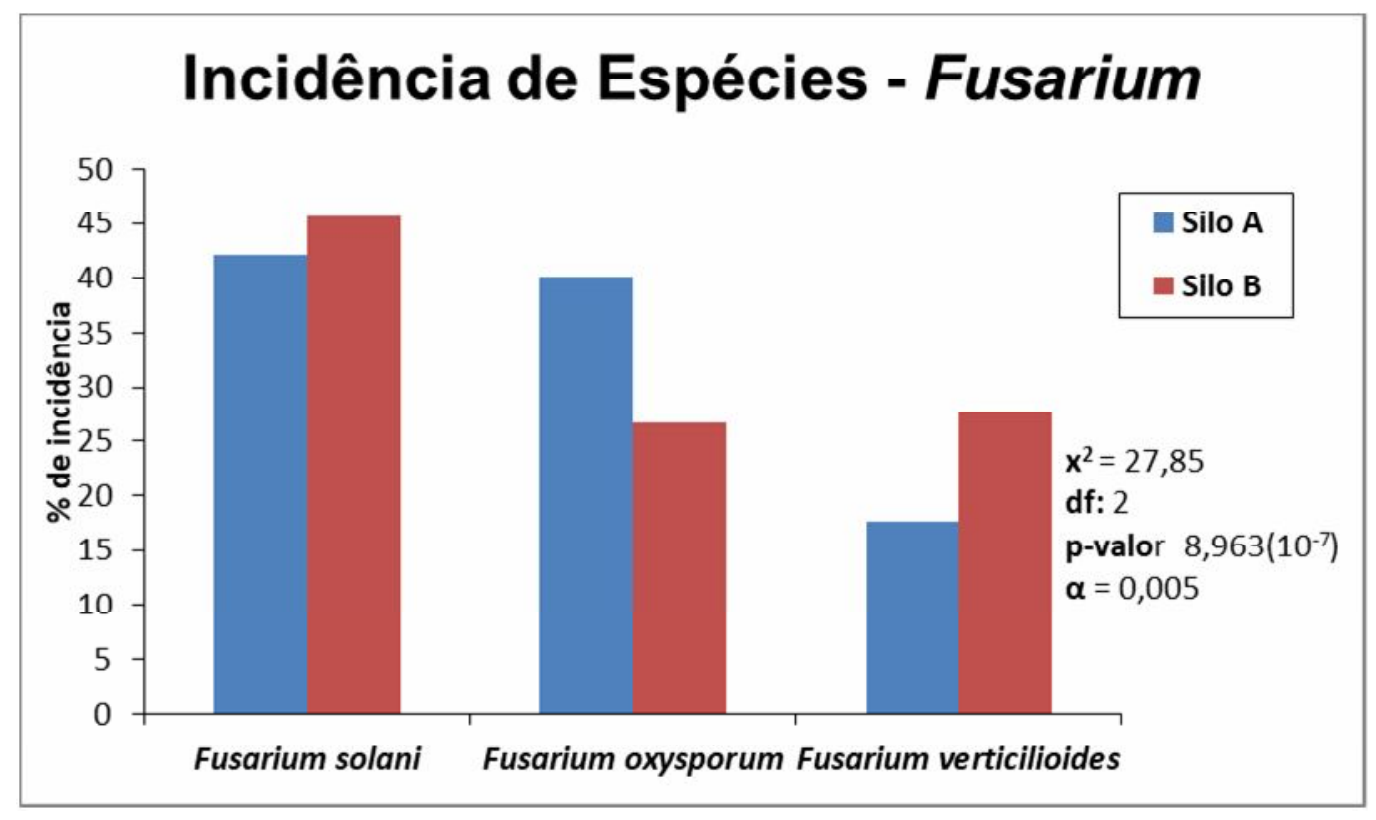

É possível observar que os níveis de incidência de Fusarium no silo de Senador Guiomar se sobressai aos de Capixaba, exceto a espécie de Fusarium oxysporum que no silo de Capixaba apresenta níveis mais elevados que os presentes no município de Senador Guiomard.

Acredita-se que o motivo de maior incidência fúngica no município de Senador Guiomard, se deve ao fato do silo receber grãos de vários produtores, como também de outro estado, possibilitando, assim, maiores níveis de contaminação.

A incidência fúngica em grãos de milho armazenados em silos, observado no presente estudo, tem grande relevância no contexto microrregional, pois visa minimizar os impactos negativos e até perdas de produção, favorecendo a viabilidade econômica de pequenas propriedades, bem como, a comercialização em larga escala.

No decorrer da pesquisa observou-se uma maior incidência de fungos de campo (Fusarium), em relação a fungos de armazenamento (Penicillium e Aspergillus), que era o esperado. Assim, acredita-se que tal acontecimento esteja relacionado às práticas de manejo aplicadas em campo.

Desta forma, como alternativa de controle de patógenos, sugere-se as práticas culturais, como a rotação de culturas e a eliminação de restos culturais, eliminando hospedeiros alternativos e reduzindo o potencial de inóculo para a cultura subsequente.

Vale ressaltar que é imprescindível saber a procedência do lote de semente que será implementado no processo de semeadura, sendo importante saber se está trabalhando com sementes idôneas, livres de patógenos.

\section{CONCLUSÃO}

Os resultados da classificação de grãos indicaram que mesmo durante o período de nove meses de armazenamento , os grãos mantiveram sua qualidade a 
níveis aceitáveis e foram classificados como Tipo 1. As UAGs apresentaram impurezas em todas as amostras analisadas, porém a níveis toleráveis, desta forma, não trariam danos severos aos lotes.

Os grãos de milho armazenados nos municípios de Capixaba e Senador Guiomard no Estado do Acre apresentaram contaminação por fungos patogênicos, Fusarium, Aspergillus e Penicillium.

A identificação morfológica revelou a prevalência do gênero Fusarium em relação aos gêneros Aspergillus e Penicillium, tanto nos grãos ardidos quanto nos assintomáticos. Os resultados evidenciaram que o gênero Fusarium foi o que mais acometeu os grãos de milho.

Foram identificados espécies de F. solani, F. oxysporum e F. verticilioide.

\section{REFERÊNCIAS}

AGBETIAMEH, D.; ORTEGA-BELTRAN, A.; AWUAH, R.T.; ATEHNKENG, J.; ISLAM, M.; CALLICOTT, K.A.; COTTY, P.J.; BANDYOPADHYAY, R. Potential of atoxigenic Aspergillus flavus vegetative compatibility groups Associated with maize and groundnut in Ghana as biocontrol agents for aflatoxin management. Frontiers in

Microbiology, $\quad$ v. $10,2019.2$ Disponível <https://www.frontiersin.org/articles/10.3389/fmicb.2019.02069/full>. $\quad$ DOI: https://doi.org/10.3389/fmicb.2019.02069

BRASIL. Ministério Da Agricultura, Pecuária e Abastecimento. Regras para análise de sementes. Secretaria de Defesa Agropecuária. - Brasília: Mapa/ACS, 2009. p. 399. Disponível em: <https://www.gov.br/agricultura/pt-br/assuntos/insumosagropecuarios/arquivos-publicacoes-insumos/2946_regras_analise_sementes.pdf $>$.

BRASIL. Ministério da agricultura, pecuária e abastecimento. Instrução normativa no 60/2011, de 22 de dezembro de 2011. Disponível em: $<$ https://www.gov.br/agricultura/pt-br/assuntos/inspecao/produtos-vegetal/legislacao1/normativos-cgqv/pocs/instrucao-normativa-no-60-de-22-de-dezembro-de-2011milho/view\#: :text=Define\%200\%20padr\%C3\%A30\%20oficial\%20de,referentes\%20 $\%$ C3\%A0\%20classifica\%C3\%A7\%C3\%A30\%20do\%20produto>.

BRASIL. Ministério Da Agricultura, Pecuária e Abastecimento, Instrução Normativa no 40/2010, mai., 2018. Disponível em: < https://www.gov.br/agricultura/ptbr/assuntos/insumos-agropecuarios/insumos-agricolas/sementes-e-

mudas/publicacoes-sementes-e-mudas/INN40de30denovembrode2010.pdf>.

BERTUZZI, T.; ROMANI, M.; RASTELLI, S.; GIORNI, P. Mycotoxins and Related Fungi in Italian Paddy Rice During the Growing Season and Storage. Toxins, v. 11, n. 3 2019. Disponível em: https://www.ncbi.nlm.nih.gov/pmc/articles/PMC6468681/>. DOI: 10.3390/toxins 11030151

CALIXTO JUNIOR, M.; JOBIM, C. C.; OSMARI, M. P; TRES, T. T. Nutritional additives in high moisture corn silage. Revista Brasileira de Ciências Agrárias, v. 12, p. 105-111. 2017. Disponível em: <https://www.redalyc.org/articulo.oa?id=119050448017>. $\quad$ DOI: 10.5039/agraria.v12i1a5413 
CONAB - Companhia Nacional de Abastecimento, Boletim Técnico: Série Armazenagem / Companhia Nacional de Abastecimen- to - v.1 (2015- ). - Brasília : Conab, 2015- v. 1, n. 1

Disponível em: <file://C:/Users/55689/Desktop/artigos\%20recentes/2015__Boletim_Tecnico_de_Armazenagem_-_Amostragem_de_Graos\%20(1).pdf>.

CONAB - Companhia Nacional de Abastecimento, 2018. Grãos: Série Histórica 2016/2017. Disponível em: <http://www.conab.gov.br>.

CONAB - Companhia Nacional de Abastecimento.; Acompanhamento da Safra Brasileira de Grãos. SAFRA 2017/2018, v.5, 2018.

DWEBA, C.C.; FIGLAN, S.; SHIMELIS, H.A.; MOTAUNG, T. E.; SYDENHAM, S.; MWADZINGENI, L.; TSILO, T. J. Fusarium head blight of wheat: pathogenesis and control strategies. Crop Protection, v. 91, p. 114-122, 2017.

Disponível

em: <https://www.sciencedirect.com/science/article/abs/pii/S0261219416302794?via\%3D ihub>. DOI: https://doi.org/10.1016/j.cropro.2016.10.002

EMBRAPA. Micotoxinas: importância na alimentação e na saúde humana e animal. Fortaleza: Embrapa Agroindústria Tropical, 2007. 48p. Disponíveis: $<$ https://www.embrapa.br/busca-de-publicacoes/-/publicacao/427374/micotoxinasimportancia-na-alimentacao-e-na-saude-humana-e-animal>.

GOMES, D. P.; KRONKA, A. Z.; PANIZZ, R. C.; BARROZO, L. M.; SILVA, R. P.; SILVA, B. M. S.; REIS, V. C. M. Influência de fatores da colheita mecanizada na incidência de fungos em sementes de milho. Brazilian Journal of Development. v.6, n.10, p.82668-82677, 2020. Disponivel em: $<$ https://www.brazilianjournals.com/index.php/BRJD/article/view/18970/15250>. DOI:10.34117/bjdv6n10-627

HAWKINS, N.J.; BASS, C.; DIXON, A.; NEVE, P. The evolutionary origins of pesticide resistance. Biological Reviews, v. 94, n. 1, p. 135-155, 2018. Disponível em: < https://pubmed.ncbi.nlm.nih.gov/29971903/>. Doi: 10.1111/brv.12440

LANZA, F. E.; ZAMBOLIM, L.; COSTA, R. V.; FIGUEIREDO, J. E. F.; SILVA, D. D.; QUEIROZ, V. A. V.; GUIMARÃES, E. A.; COTA, L. V. Symptomatological aspects associated with fungal incidence and fumonisin levels in corn kernels. Tropical plant pathology, v. 42, p. 304-308, 2017. Disponível em: <http://www.alice.cnptia.embrapa.br/alice/handle/doc/1071843>. DOI: 10.1007/s40858-017-0148-2

LAZZARI, F.A. Umidade, fungos e micotoxinas na qualidade de sementes, grãos e rações. 2a Edição. Curitiba, Ed. do Autor, 140p, 1997. Disponível em: < http://periodicos.ses.sp.bvs.br/pdf/rial/v64n1/v64n1a14.pdf>.

LUDEMANN, V. GRECO, M.; RODRíGUEZ, M. P; BRASÍLICO, J. C.; PARDO, A. G. Conidial production by Penicillium nalgiovense for use as starter cultures in dry fermented sausages by solid state fermentation. Food Science and Technology, v. 43, n. $2, \quad$ p. $315-318,2010 . \quad$ Disponível: 
https://www.sciencedirect.com/science/article/abs/pii/S0023643809002096>.

DOI: https://doi.org/10.1016/j.Iwt.2009.07.011

MARCIA, B. A.; LAZZARI, F. A. Monitoramento de fungos no milho em grão, grãos e farinha de milho. Ciência e Tecnologia de Alimentos, v. 18, n. 4, p. 363-367, 1998. Disponível em:

https://www.scielo.br/j/cta/a/tWktchcCHSVpdhKKML4tVWq/?lang=pt>.

DOI: https://doi.org/10.1590/S0101-20611998000400001

MARIN, S.; SANCHIS V.; RAMOS, A. J.; VINAS, I.; MAGAN, N. Environmentalfactors, in-vitro interactions, and niche overlap between Fusarium moniliforme, $F$. proliferatum, and F. graminearum, Aspergillus and Penicillium species from maize grain. Mycological Research, v. 102, n. 7, p. 831-837, 1998. Disponível em: < https://www.sciencedirect.com/science/article/abs/pii/S0953756208609557>. DOI: https://doi.org/10.1017/S0953756297005777

MATHIAS, T.R.S.; MENEZES, L.M.; SÉRVULO, E.F.C. Effect of maize as adjunct and the mashing proteolytic step on the brewer wort composition. Beverages, v. 5, n. 4, 2019. Disponível em: <https://www.mdpi.com/2306-5710/5/4/65>. DOI: https://doi.org/10.3390/beverages5040065

MENEZES M, ASSIS SMP (2004). Guia prático para fungos fitopatogênicos. $2^{\mathrm{a}}$ ed. Recife PE. Imprensa Universitária da UFRPE.

MISTURA, M.; LINDINO, C. A. Incidência de micotoxinas em milho nos estados do Paraná, Mato Grosso E Mato Grosso Do Sul entre 2015 e 2018, Brazilian Journal of Development, v. 6, n. 10, p. 76671-76688, 2020.

Disponível

em:

<https://www.brazilianjournals.com/index.php/BRJD/article/view/17988>. $\quad$ DOI: DOI:10.34117/bjdv10-188.

MOTTA, T. P. FRIZZARIN, A.; MARTINS, T.; MIRANDA, M. S.; ARCARO, J. R. P.; AMBRÓSIO, L. A.; POZZI, C. R. Estudo sobre a ocorrência de fungos e aflatoxina B1 na dieta de bovinos leiteiros em São Paulo. Pesquisa Veterinária Brasileira, v. 35, n. 1, p. 23-28, 2015. Disponível em: < https://www.scielo.br/j/pvb/a/zxWH7pNC5Cpj7qPv3vvsrfF/?format=pdf\&lang=pt>.

Doi: 10.1590/S0100-736X2015000100006

MUNKVOLD, G.P. Fusarium species and their associated mycotoxins. In: Clifton, N.J. (Comp.). Mycotoxigenic fungi: methods and protocols. Human Press. New York p. 51-106. 2017. Disponível em: <https://pubmed.ncbi.nlm.nih.gov/27924531/>. DOI: 10.1007/978-1-4939-6707-0_4

NEUMANN, M., LEÃO, G. F. M., COELHO, M. G., FIGUEIRA, D. N., SPADA, C. A. \& PERUSSOLO, L. F. Aspectos produtivos, nutricionais e bioeconômicos de híbridos de milho para produção de silagem. Archivos de Zootecnia, v. 66, p. 51-58, 2017. Disponível em: < https://www.redalyc.org/articulo.oa?id=49551221008>.

OLIVEIRA, M. S.; ROCHA, A.; SOLYOK, M.; KRSKA, R.; MALLMANN, C. A; Natural mycotoxin contamination of maize (Zea mays L.) in the South region of Brazil. Food 
Control, v. 73, p.127-132, 2017. Disponível em: < https://www.sciencedirect.com/science/article/pii/S0956713516304030>. DOI: https://doi.org/10.1016/j.foodcont.2016.07.033

PATINDOL, J.; WANG, Y. J. Fine structures and physicochemical properties of starches from chalky and translucent rice kernels. Journal of Agricultural and and Food Chemistry, v. 51, n. 9, p. 2777-2784, 2003.

Disponível em: <https://pubs.acs.org/doi/10.1021/jf026101t>. DOI: https://doi.org/10.1021/jf026101t

PALHARI, C.C.; ALVES, L.B.; SOUZA, M.C.; CORREA, E.B.; BEZERRIL, J.E.; ROMANI, I. Intoxicação aguda por micotoxina em suínos: relato de caso. Revista UNINGÁ Review, v. 34, n. 1, p.33-33, 2019. Disponível em: < http://revista.uninga.br/index.php/uningareviews/article/view/3095>.

PRESTES, I. D.; ROCHA, L. O.; NUÑEZ, K. V. M; SILVA, N. C. C. Principais fungos e micotoxinas em grãos de milho e suas consequências. Scientia Agropecuaria, v. 10, n.4, p.559-570, 2019. Disponível em: $<$ https://revistas.unitru.edu.pe/index.php/scientiaagrop>. DOI: 10.17268/sci.agropecu.2019.04.13

SANTOS, G., MORAES, J. M. M.; NUSSIO, L. G. Custo e análise de sensibilidade na produção de silagem. Revista iPecege, v. 3, p. 39- 48, 2017. Disponível em: $<$ https://revista.ipecege.org.br/Revista/article/view/100>.

DOI: https://doi.org/10.22167/r.ipecege.2017.1.39

SENAR - Serviço Nacional de Aprendizagem Rural. Grãos: armazenamento de milho, soja, feijão e café. Brasília: Senar, 2018. 100 p.; il. - (Coleção SENAR 216) Disponível em: <https://www.cnabrasil.org.br/assets/arquivos/216ARMAZENAMENTOS-GR\%C3\%83OS-NOVO.pdf>

TADEI, N. S. SILVA, N. C. C.; IWASE, C. H. T.; ROCHA, L. O. Micotoxinas de Fusarium na produção de cerveja: características, toxicidade, incidência, legislação e estratégias de controle. Scientia Agropecuaria, v. 11, n. 2, p. 247-256, 2020. Disponivel em: <http://www.scielo.org.pe/scielo.php?script=sci_arttext\&pid=S207799172020000200247\&lng=es\&nrm=iso >.

DOI: http://dx.doi.org/10.17268/sci.agropecu.2020.02.13

TANAKA, M. A. S.; MAEDA, J. A.; PLAZAS, I. H. A. Z. Microflora fúngica de sementes de milho em ambientes de armazenamento. Scientia Agricola, v. 58, n. 3, 501- 508, $2001 . \quad$ Disponível: <https://www.scielo.br/j/sa/a/7VnBPVxfMMCwwh8HfZrczRd/abstract/?lang=pt>. DOI: https://doi.org/10.1590/S0103-90162001000300011

VALMORBIDA, R. Quality and safety of maize (Zea mays L.) from Rondônia state storage units, Northern Brazil. Food Microbiology, p. 54-63, 2018.

Disponível em: <https://pubmed.ncbi.nlm.nih.gov/29145779/>. DOI: 10.1080/19393210.2017.1403967 
XING, F.; LIU, X.; WANG, L.; SELVARAJ., J.N.; NUO, S.; WANG, N.; ZHAO, Y.; LIU, Y.; Distribution and variation of fungi and major mycotoxins in pre- and post-nature drying maize in North China Plain. Food Control, v. 80, P 244-251, 2017. Disponível em: <https://www.sciencedirect.com/science/article/abs/pii/S0956713517301366>. DOI: https://doi.org/10.1016/j.foodcont.2017.03.055 